\title{
Investigando o desenvolvimento do raciocínio lógico matemático em crianças entre 11 e 12 anos através dos cursos da Academia Hacktown
}

\author{
Investigating the development of mathematical logical reasoning in children \\ between 11 and 12 years old through Hacktown academy courses
}

BARROS, Luís Carlos Aquino. Graduando em Sistemas para Internet.

Instituto Federal do Sertão Pernambucano - Campus Salgueiro. BR 232, Km 504, sentido Recife, Zona RuraSalgueiro - Pernambuco - Brasil. CEP: 56000000 / Telefone: (87) 3421.0050 / E-mail:

luiscarlosaquino14@gmail.com

\section{MARQUES, Maria Alice de Freitas. Mestre em Educação}

Instituto Federal do Sertão Pernambucano - Campus Salgueiro. BR 232, Km 504, sentido Recife, Zona RuraSalgueiro - Pernambuco - Brasil. CEP: 56000000 / Telefone: (87) 3421.0050 / E-mail: alice.freitas@ifsertaope.edu.br

\section{RESUMO}

O raciocínio lógico é uma característica fundamental a qualquer ser humano, entretanto, está sendo perdida com o tempo. 0 avanço da tecnologia que trouxe diversos benefícios para a sociedade, também está criando uma geração de pessoas acomodadas, que buscam em seus dispositivos eletrônicos todas as respostas para os seus problemas e não se indagam sobre o que encontram, são apenas reprodutores de ideias já existentes ao invés de formar suas próprias concepções. Assim, é necessário medidas para estimular essa geração a pensar e utilizar o raciocínio lógico. Diante deste cenário, a Academia Hacktown surge como uma ótima alternativa para que através das suas metodologias de ensino possa oportunizar tais estímulos. Sendo assim, este trabalho teve como objetivo investigar a evolução do desenvolvimento do raciocínio lógico em crianças de 11 e 12 anos nos cursos da Academia Hacktown através de testes matemáticos aplicados ao início e ao final do curso. Para cumprir os objetivos o trabalho foi dividido em quatro passos, analisar realizando um teste em que situação de desenvolvimento do raciocínio lógico os alunos ingressantes na academia estão, ministrar o curso da academia, através de um teste avaliar o desenvolvimento do raciocínio lógico após o curso e ao final realizar um comparativo entre os testes inicial e final para analisar se houve melhora no desenvolvimento dos alunos. Com duração de sessenta horas, o curso alcançou ao final resultados satisfatórios acerca dos objetivos propostos.

Palavras-chave: Raciocínio lógico; Desenvolvimento; Academia Hacktown.

\section{ABSTRACT}

Logical reasoning is a fundamental trait to any human being, however, it is being lost over time. The advancement of technology that has brought many benefits to society is also creating a generation of well-to-do people who seek in their electronic devices all the answers to their problems and do not ask what they find, they are only reproducers of existing ideas rather than forming their own conceptions. Thus, measures are needed to stimulate this generation to think and use logical reasoning. Given this scenario, the Hacktown Academy appears as a great alternative so that through its teaching methodologies can opportune such stimuli. The aim of this work was to investigate the development of logical reasoning in children aged 11 and 12 years in hacktown academy courses through mathematical tests applied at the beginning and end of the course. To accomplish the objectives the work was divided into four steps, analyzing by carrying out a test in which situation of development of logical reasoning the students entering the academy are, to minister the course of the academy, through a test to evaluate the development of logical reasoning after the course and in the end to make a comparative between the initial and final tests to analyze if there was improvement in the development of the students. With a duration of 60 hours, the course reached satisfactory results on the proposed objectives.

Keywords: Logical reasoning; Development; Hacktown Academy. 
BARROS, L, C, A; FREITAS, M, A;

Investigando O Desenvolvimento Do Raciocínio Lógico Matemático Em Crianças Entre 11 E 12 Anos Através Dos Cursos Da Academia Hacktown

Introdução

Possuir um bom raciocínio lógico é algo essencial na formação educacional de um indivíduo atualmente, devido às demandas do mercado profissional, pois ao longo da vida produtiva ou pessoal nos deparamos com diversas problemáticas, onde em sua maioria, pensar de forma lógica e objetiva é a melhor forma de se encontrar soluções rápidas e efetivas para tais demandas.

A necessidade do uso do raciocínio lógico se apresenta frequentemente em situações do cotidiano, seja na tomada rápida de decisões, na interpretação de textos, nas formas de expressarse, como também na resolução de problemas matemáticos (MARTINS et al., 2015, p.1.).

0 raciocínio lógico sempre foi uma grande ferramenta do homem para resolução dos seus problemas, porém o ato de pensar que caracteriza o homem como ser racional vem se perdendo com o tempo, devido à acomodação por causa das novas tecnologias, as novas gerações não são estimuladas a pensar, sendo apenas reprodutores de ideias já existentes, invés de desenvolverem seus próprios pensamentos. Essa acomodação faz com que muitas pessoas tenham dificuldade em resoluções de problemas matemáticos. Isso está ocasionando uma grande dificuldade no ensino da matemática, devido ao fato dos jovens não precisarem exercitar diariamente o raciocínio, onde encontram na internet a solução para seus problemas.

O nível de aprendizado dos estudantes brasileiros no ensino médio piorou em matemática e chegou, em 2015, ao pior resultado desde 2005, início da série histórica do Saeb¹. (SALDAÑA, 2016).

Sendo assim se faz preciso a retomada dessa característica que faz com que o ser humano seja considerado um ser racional. Fazendo assim a nossa sociedade mais intelectual, onde as pessoas possam encontrar de maneira prática e rápida soluções para seus problemas diários.

Porém como afirma Piaget (1978) conforme citado por Martins et al. (2015, p.2) em sua grande contribuição com o estudo do raciocínio lógico matemático: “O conhecimento lógico matemático resulta da ação mental da criança sobre os objetos. Portanto, ele não pode ser ensinado por repetição ou verbalização".

Tendo em vista esses fatores, as escolas não estão conseguindo fazer com que seus alunos adquiram esse raciocínio, crianças estão saindo do ensino fundamental e ingressando no ensino médio com grande dificuldade na aprendizagem da matemática. No ensino médio, a maioria dos estudantes não são capazes de resolver problemas com operações fundamentais com números naturais ou reconhecer o gráfico de função a partir de valores fornecidos em um texto (FAJARDO; FOREQUE, 2018).

Segundo afirmação do ministério da educação (MEC), 7 de cada 10 alunos do ensino médio têm nível insuficiente em português e matemática (FAJARDO; FOREQUE, 2018).

0 raciocínio lógico precisa ser estimulado através de atividades que exijam o uso do pensamento para a resolução dos problemas. Atividades que estimulam o raciocínio lógico provocam aumento do fluxo sanguíneo e de correntes elétricas no cérebro, além de incentivarem a produção de neurotransmissores. Tais efeitos melhoram a quantidade e a qualidade das conexões entre as células nervosas, o que resulta em melhores desempenhos. (MUNIZ, 2015, p.1).

\footnotetext{
${ }^{1}$ Sistema de Avaliação da Educação Básica
} 
BARROS, L, C, A; FREITAS, M, A; Investigando O Desenvolvimento Do Raciocínio Lógico Matemático Em Crianças Entre 11 E 12 Anos Através Dos Cursos Da Academia Hacktown

Assim surgem demandas de métodos alternativos para que o raciocínio lógico seja estimulado nas crianças, medidas como os cursos oferecidos pela Academia Hacktown, a academia proporciona às crianças entre 11 e 12 anos, tema da pesquisa, um curso que aborda programação em jogos e robótica, que apresenta aos alunos conceitos computacionais, como hardware e software, além dos princípios de construção de programas de computadores, com ênfase em programação utilizando a linguagem de programação Python, Minecraft, que é um jogo virtual para computadores, também é oferecido aos alunos praticas com o LEGO EV3, um robô programável criado através de blocos de construção e iniciação em robótica livre com Arduino.

Sendo assim, este trabalho teve como objetivo analisar a evolução do desenvolvimento do raciocínio lógico em crianças de 11 e 12 anos nos cursos da Academia Hacktown através de testes matemáticos, aplicados ao início e ao termino do curso. Para alcançar esses objetivos, o trabalho foi dividido em quatro etapas, a primeira etapa teve o intuito de analisar através de um teste com questões de raciocínio lógico matemático em que situação do desenvolvimento do raciocínio lógico os alunos ingressantes da academia estão, na segunda etapa será ministrado o curso da academia de forma lúdica e divertida para assim proporcionar uma boa experiência para os alunos, a terceira etapa consiste novamente na aplicação do teste, para obter dados de qual estado o desenvolvimento do raciocínio dos alunos está após o curso e por último a realização de um comparativo acerca do desenvolvimento do raciocínio lógico matemático e outras atividades cognitivas após o término do curso. Os resultados obtidos foram satisfatórios acercas dos objetivos do trabalho. A próxima sessão mostrará detalhadamente os objetivos deste trabalho.

\section{Revisão de Literatura}

\section{Academia Hacktown}

Academia Hacktown é a primeira escola pública de programação em jogos e robótica, surgiu no Instituto Federal do Sertão Pernambucano, por iniciativa do professor Fábio Cristiano, do colegiado de Licenciatura em computação do campus Petrolina. O projeto teve início no final de 2014, fruto de parcerias com a Secretaria de Educação Profissional e Tecnológica (Setec), do Ministério da Educação (MEC) e com o Conselho Nacional de Desenvolvimento Cientifico e Tecnológico (CNPq). Os cursos da academia são ministrados por bolsistas do ensino médio e superior na área de informática, divididos entre instrutores que tem a responsabilidade de conduzir as turmas, sendo esses exclusivamente acadêmicos no ensino superior e os monitores que prestam auxilio na elaboração e aplicação das aulas, sendo eles do ensino médio. (AUGUSTO; BRANDÃO, 2018, pag. 17).

\section{Metodologias de ensino da Academia Hacktown}

\section{Computação desplugada}

É uma forma de ensinar os conceitos básicos da computação, sem o uso de computadores, através de atividades lúdicas (jogos e dinâmicas), facilitando a aprendizagem de uma maneira 
BARROS, L, C, A; FREITAS, M, A;

Investigando O Desenvolvimento Do Raciocínio Lógico Matemático Em Crianças Entre 11 E 12 Anos Através Dos Cursos Da Academia Hacktown

interativa e divertida sem o uso do computador. Estas atividades normalmente envolvem conceitos matemáticos, de tecnologia e de computadores e estimulam a comunicação, a resolução de problemas e a criatividade dos alunos. (METODOLOGIAS).

Ensinar os conceitos teóricos sobre ciências da computação não é uma tarefa fácil, sobretudo quando seu público alvo trata-se de crianças. Por possuir uma personalidade agitada e inquieta, geralmente o ensino de qualquer teoria nos moldes da educação tradicional, acaba se tornando uma experiência chata para elas, por isso a computação desplugada tornou-se um ótimo método de ensino, uma vez que sua forma clara de mostrar os conteúdos através de atividades dinâmicas fazem com que as crianças tenham um melhor entendimento sobre o assunto.

Trazer as crianças uma forma divertida de aprender, brincando, desperta nelas o desejo de continuar aprendendo. A incorporação de brincadeiras na prática pedagógica desenvolve diferentes atividades que contribuem para inúmeras aprendizagens e para a ampliação da rede de significados construtivos tanto para a criança quanto para jovens e adultos. (OLIVEIRA, 2011).

\section{Gamificação}

De acordo com Karl Kapp “Gamification é a utilização de mecânica, estética e pensamento baseados em games para engajar pessoas, motivar a ação, promover a aprendizagem e resolver problemas". Assim, na academia fazemos uso da tecnologia a partir da linguagem de jogos e games que fascinam os alunos. Sejam coletivamente ou individualmente, os alunos participam de atividades que promovem disputas com pontos, rankings, prêmios e qualquer elemento da mecânica de jogo para diferentes atividades, tornando-as mais divertidas, promovendo o engajamento, estimulam a criatividade, a resolução de problemas, autonomia, o diálogo, dentre outras. (METODOLOGIAS).

\section{Aprendizagem significativa}

Aprendizagem significativa parte do pressuposto que como seres humanos somos incompletos, precisamos nos autoconstruir, por isso, necessitamos aprender a falar, a se relacionar, a viver em comunidade. Entretanto, nem tudo que aprendemos tem um significado. (METODOLOGIAS).

Por isso, torna-se necessário conhecer o que o aluno sabe, para que a partir disso possa ser proposto o conteúdo que faça uma ligação dos conhecimentos que o aluno possui os que the será ensinado, de forma que haja para o aluno um significado do que ele está aprendendo.

Assim, as atividades propostas nos cursos da academia buscam que os alunos tenham problemas a resolver e decisões a tomar, possibilitando a reflexão das escolhas feitas e construção/significado do conhecimento. (METODOLOGIAS).

Ao decorrer do curso, essa metodologia foi constantemente utilizada, onde além de aprender, os alunos entendiam para que estavam aprendendo determinado conteúdo, assim, as 
BARROS, L, C, A; FREITAS, M, A;

Investigando O Desenvolvimento Do Raciocínio Lógico Matemático Em Crianças Entre 11 E 12 Anos Através Dos Cursos Da Academia Hacktown

atividades tornavam -se fáceis de serem entendidas, sendo que os alunos se concentravam mais na hora de aprender, devido conhecerem o porquê que tinham que aprender aquela informação.

\section{Game learning}

Envolve a união de um videogame, uma história, usando elementos de gamificação, um simulador e um conteúdo teórico. À medida que enfrenta os desafios, os alunos necessitam aplicar a teoria para progredirem no jogo e recebem feedback personalizados sobre o desempenho. Ao fazer uso dessa metodologia observa-se uma maior motivação na compreensão, retenção e memorização dos conteúdos. (METODOLOGIAS).

Essa metodologia tornou o aprendizado das crianças mais divertido, estamos vivendo em geração em que os jogos eletrônicos estão em alta entre jovens e crianças, assim, moldar o curso as características de um jogo tornaram o ensino mais interessante para os alunos. Assim como jogo, o curso foi dividido em fases, no qual os alunos deveriam seguir uma história definida para o curso, e a cada fase ir realizando atividades que foram denominadas como missões, para que assim ganhassem pontos e concluíssem a história do curso.

\section{Story telling}

O storytelling é a contação de histórias por meio de mídias, em diversas plataformas digitais na difusão de informações gerando interação com o público (DOMINGOS, 2009). Seu uso abrange a educação, empresas e jogos digitais. Na educação pode ser considerada como a antiga arte da contação de histórias que foi adaptada com o uso de tecnologias disponíveis (DOMINGOS, 2012). Em jogos digitais, faz parte de sua estrutura e envolve o jogador que acaba por fazer parte dela, vivenciando e participando de seu desenvolvimento no jogo (LEBOWITZ; KLUG, 2011). Essa interação do jogador com a história tem seu fator de engajamento e pode ser utilizada em sala de aula em conjunto com elementos e mecânicas de jogos. (METODOLOGIAS).

Essa contação de história envolve os alunos no curso, como se realmente estivessem em um jogo, no qual necessitam de uma história para que possam cumprir determinadas missões, onde além de guia - lós a história os faz entender o porquê devem cumprir as missões propostas.

\section{Metodologia de pesquisa}

trabalho foi dividido em etapas, onde inicialmente foram realizadas pesquisas bibliográficas acerca da temática a qual o referencial teórico irá se basear, assim como a definição de cada etapa a ser seguida para a concretização dos objetivos. Após a definição a metodologia teve seu corpo dividido em três fases experimentais em campo, análise inicial, aplicação do curso e avaliação final. A análise inicial consiste em avaliar o conhecimento e as capacidades de raciocínio lógico iniciais que os alunos possuem antes do curso, sendo essas informações muito importantes para que ao final do curso haja informações concretas se houve de fato evolução. 
BARROS, L, C, A; FREITAS, $M, A$;

Investigando O Desenvolvimento Do Raciocínio Lógico Matemático Em Crianças Entre 11 E 12 Anos Através Dos Cursos Da Academia Hacktown

\section{Análise inicial}

$\mathrm{Na}$ primeira etapa, os alunos ingressantes no curso referente a turma kids 2 da Academia Hacktown, foram submetidos a realização de um teste matemático de raciocínio lógico, composto por oito questões de múltipla escolha, o teste apresentou questões no qual seria necessário pensar e utilizar lógica para chegar à resposta. 0 teste teve o objetivo de avaliar o conhecimento e a capacidade dos alunos para resolver problemas lógicos, no qual o ato de pensar é a melhor ferramenta para essa resolução. 0 teste foi aplicado e avaliado.

\section{Aplicação do curso}

Na segunda etapa, foi realizado o curso da Academia Hacktown referente a turma alvo da pesquisa. 0 curso tem 60 horas e foi dinamicamente dividido em seis fases, para trazer aos alunos um melhor aprendizado e absorção dos conteúdos. Cada fase proporciona ao aluno uma nova experiência, sempre de forma lúdica, os ensinamentos são passados de maneira a atrair o interesse dos alunos, para que os mesmos sintam - se desafiados a buscar mais conhecimentos. Porém, despertar a curiosidade e o interesse dos alunos não é algo simples, entretanto existem algumas formas. Para Rogers (1969, p. 157 - 63) conforme citado por Moreira (1999, cap.9)," A aprendizagem é facilitada quando o aluno participa responsavelmente do processo de aprendizagem".

Para despertar de fato o prazer dos alunos em participarem do curso, a academia ciente da influência que os jogos eletrônicos tem sobre as crianças e adolescentes da nova geração, atribuiu ao curso os conceitos de gamificação, para transformar as aulas em algo que os alunos já estão habituados e que os traz interesse e conforto, trazendo a eles termos e mecânicas comuns a qualquer game, ranking de pontuação, missões e fases são alguns exemplos das mecânicas que compõe o curso. Conciliado a isso, a academia também trouxe ao curso o game learning, que juntou os elementos da gamificação a uma boa história, para fazer com que os alunos além de cursar, possam de fato vivenciar o curso, fase após fase, seguindo uma história, até conseguirem "zerar o jogo kids 2", ou seja, concluir o curso.

\section{Etapas do curso}

\section{Fase 1 - Computação desplugada}

Os alunos ingressantes da academia, por se tratarem de crianças, a grande maioria ingressa no curso leigos em assuntos tecnológicos, sendo assim a primeira fase do curso teve o objetivo de apresentar aos alunos os conceitos básicos sobre ciências da computação. De forma interativa, através dos conceitos de computação desplugada, os alunos foram ensinados sobre assuntos como: o que é um computador, o que são softwares e hardwares, o que é internet e como ela funciona, dentre outros temas. Sem o uso do computador, foram inseridos brincadeiras e desafios para deixar 
BARROS, L, C, A; FREITAS, M, A; Investigando O Desenvolvimento Do Raciocínio Lógico Matemático Em Crianças Entre 11 E 12 Anos Através Dos Cursos Da Academia Hacktown

a aula mais descontraída e interessante aos alunos, fugindo assim da forma de ensino tradicional, onde o aluno senta e apenas escuta o que o professor tem a falar. A academia insere diretamente as crianças nas aulas, para que elas percebam a importância do que the está sendo ensinado e para que possa despertar o desejo de seguir no curso e buscar novas conhecimentos.

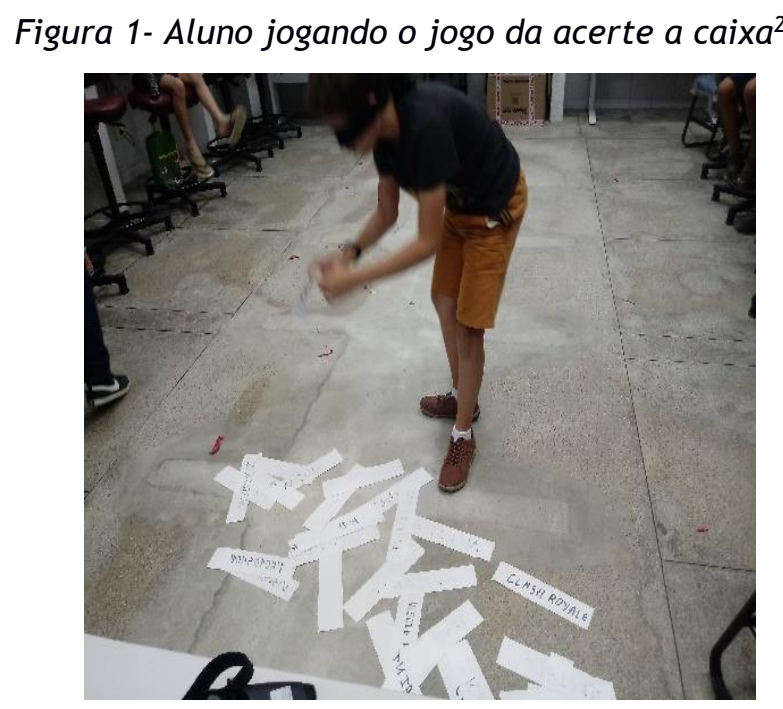

Fonte 1- Foto capturada pelo autor.

\section{Fase 2 - Introdução a lógica de programação}

Na segunda fase, deu - se início a programação, de forma inicial, os alunos construíram seus primeiros programas de computador através da linguagem Portugol. Essa inserção na programação através da linguagem Portugol é essencial, pois por não possuírem experiência em programação, uma linguagem simples, que mostre aos alunos do que se trata a programação e que os faça entender a lógica, proporciona aos alunos inicialmente um bom entendimento, para que possa assim minimizar suas dificuldades ao migrarem para outra linguagem.

A linguagem Portugol permite que os alunos codifiquem os seus algoritmos numa linguagem próxima da que usualmente utilizam para comunicar, que aliada a uma sintaxe simples e flexível possibilita que se concentrem na resolução dos problemas e no raciocínio abstrato do algoritmo e não no ambiente e na linguagem onde expressam esse mesmo algoritmo. Por fim, a linguagem possui algumas características presentes nas linguagens de programação mais modernas, tais como a definição de variáveis quando elas são necessárias e a definição do tipo texto como básico. (MANSO; OLIVEIRA; MARQUES, 2009).

\section{Fase 3 - Programação Python com Minecraft}

\footnotetext{
${ }^{2} \mathrm{O}$ jogo funcionou da seguinte forma, no chão estavam espalhados diversos papeis contento nomes referentes a hardware e software, o aluno vendado pegava um papel e sua equipe o guiava para que o mesmo colocasse o papel em sua devida caixa.
} 
BARROS, L, C, A; FREITAS, M, A; Investigando O Desenvolvimento Do Raciocínio Lógico Matemático Em Crianças Entre 11 E 12 Anos Através Dos Cursos Da Academia Hacktown

A fase três trouxe aos alunos a linguagem de programação Python conciliada ao jogo Minecraft, como forma de propor interatividade e diversão, sendo o Minecraft um game bastante popular principalmente entre as crianças. Por já terem aprendido lógica na fase anterior com o Portugol, os alunos levaram pouco tempo pra entender Python, assim ações básicas da programação como criar variáveis, imprimir mensagens na tela, somar números, foram realizadas de forma simples pelos alunos.

O Minecraft tem o objetivo de criar construções a partir dos recursos encontrados no próprio jogo, para o que o jogador consiga fugir dos monstros, o Python no jogo oferece muitas outras alternativas, pois invés do jogador passar dias em busca de recursos no jogo, com algumas linhas de comando ele pode construir objetos e elementos como fortalezas, rios e casas, além de poder se teletransportar a qualquer lugar dentro do jogo. Essa interação é uma forma de obter diversão, dinamicidade e interatividade no aprendizado de programação que outras linguagens não proporcionam. (DA SILVA; OLIVEIRA; MARTINS, 2017).

Figuras 2 e 3- Alunas aprendendo através do jogo Minecraft.
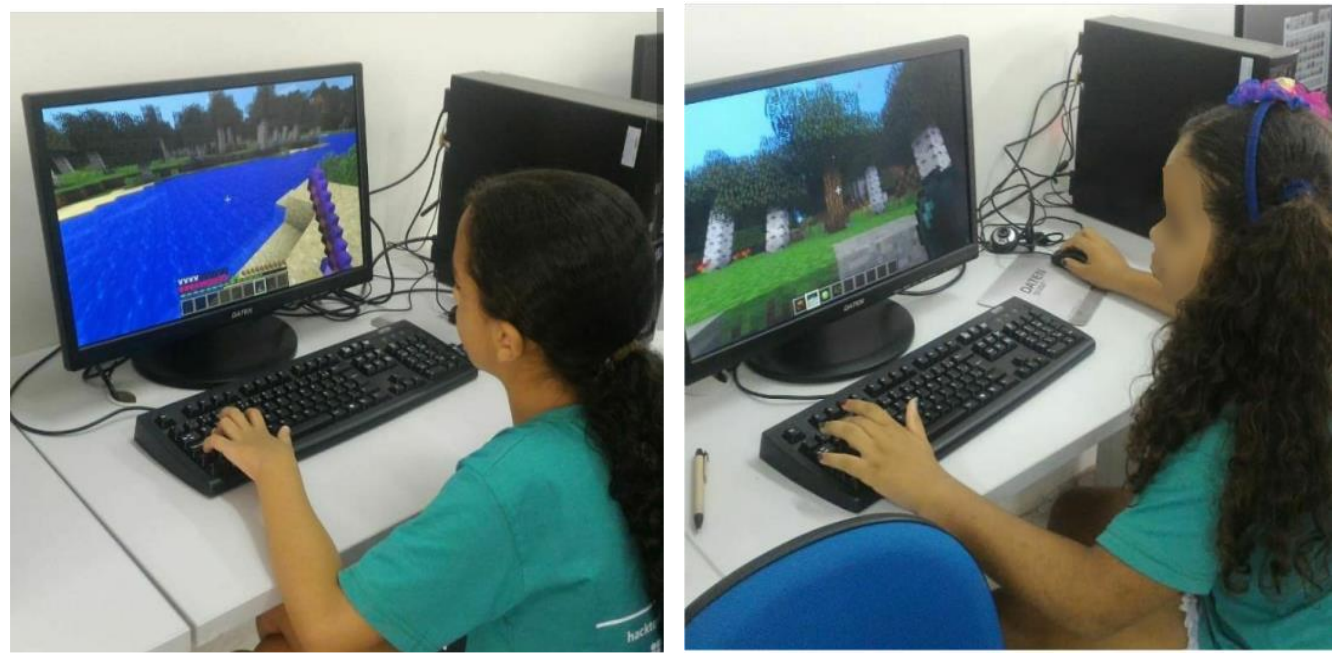

Fontes 2 e 3-Imagens capturadas pelo autor

Fase 4 - Desenvolvimento de Jogos 3D

$\mathrm{Na}$ fase quatro os alunos deram início ao desenvolvimento de jogos através da plataforma Kodu, uma experiência diferente para eles, uma vez que não seriam apenas jogadores, seriam também desenvolvedores dos seus jogos. Assim, perceberam o quão difícil é criar um bom jogo, contendo um objetivo claro e uma história atrativa, itens fundamentais de um jogo. Essa fase, exigiu muita atenção dos alunos, onde essa experiência visual com programação através de uma sequência de passos, tem como objetivo estimular e desenvolver o raciocínio lógico dos alunos. Os alunos ficaram livres para criar jogos aos seus gostos, onde através do estudo da ferramenta e da programação em blocos, criaram diversos jogos, desde jogos de sobrevivência a joguinhos de corrida. 
BARROS, L, C, A; FREITAS, M, A;

Investigando O Desenvolvimento Do Raciocínio Lógico Matemático Em Crianças Entre 11 E 12 Anos Através Dos Cursos Da Academia Hacktown

Quando o aluno é inserido num ambiente de jogo e simulação, as possibilidades de resolução de um problema deste tipo são maiores, visto que, a linguagem e a experiência visual e interativa dos jogos fazem parte de seu cotidiano. (SOUZA; DIAS, 2012).

Figuras 4 e 5- Alunos criando jogos com o Kodu.
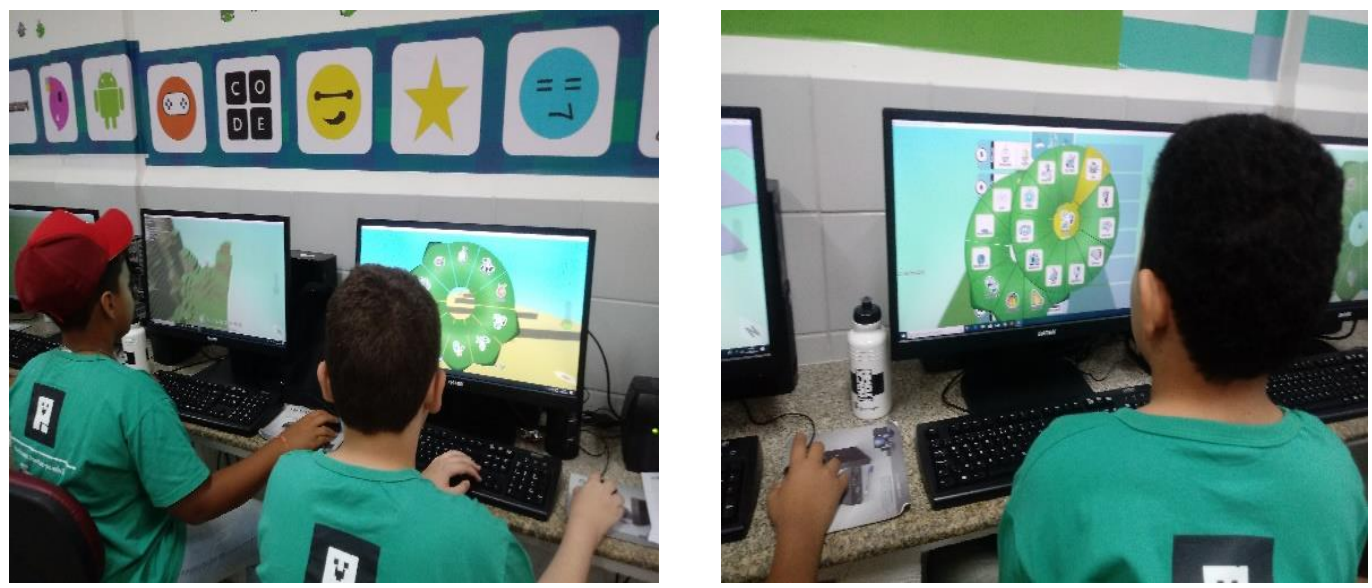

Fonte 4 e 5- Fotos capturadas pelo autor.

\section{Fase 5 - Robótica com LEGO EV3}

A fase cinco, trouxe aos alunos uma nova experiência, a robótica. Iniciada através da plataforma Lego, que realiza a montagem de robôs, carrinhos e humanoides através de peças de construção, no qual essa montagem proporcionou diversão aos alunos e exigiu muita atenção, uma vez que uma única peça montada de forma errada acarretaria no mal funcionando do robô, as crianças ao longo da fase puderam criar alguns tipos de projetos com o Lego, como a montagem e programação respectivamente do carro robô, gorila, braço robô e o giroboy (Modelos de projetos Lego).

A programação do Lego EV3 é bem simples, sendo realizada em blocos, podendo ser realizada de duas formas, diretamente no bloco ev3 e através da IDE da Mindstorms.

Essa fase foi uma das preferidas das crianças, onde de fato "botaram a mão na massa", se divertiram montando e programando e sentiram -se realizados ao ver seus projetos funcionando.

Figura 6 e 7- Alunos montando robôs com a plataforma Lego EV3
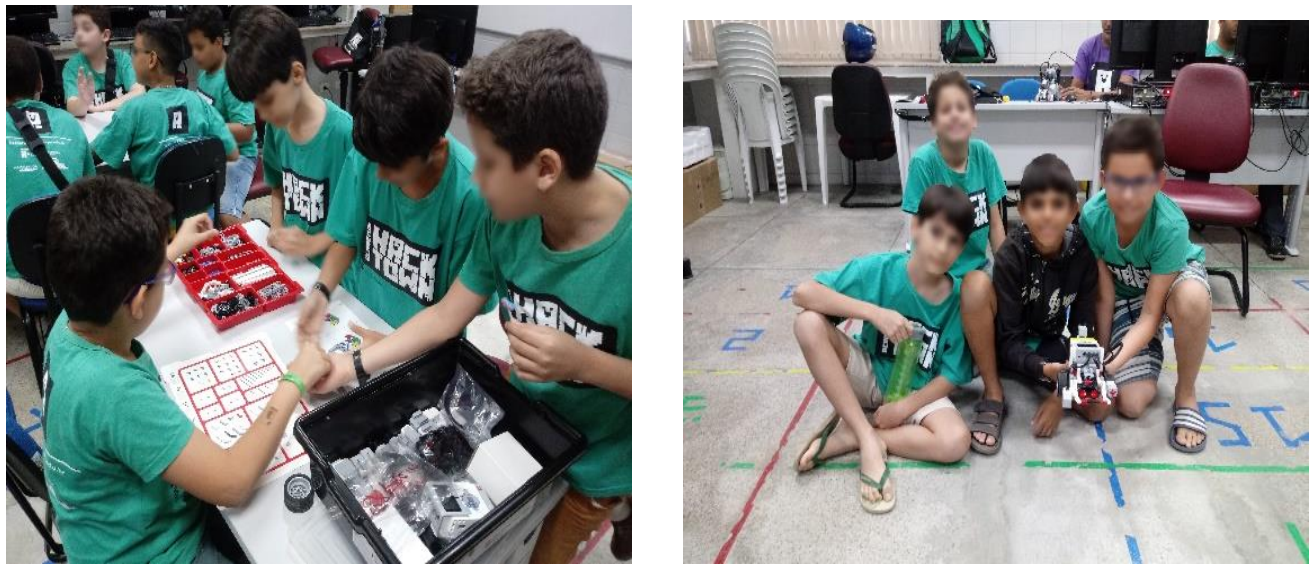

Fonte 6 e 7 - Imagens capturadas pelo autor. 
BARROS, L, C, A; FREITAS, M, A;

Investigando O Desenvolvimento Do Raciocínio Lógico Matemático Em Crianças Entre 11 E 12 Anos Através Dos Cursos Da Academia Hacktown

\section{Avaliação final}

Ao término do curso, após terem vivenciado todas as fases, todas as missões propostas ao longo do curso, foi proposto aos alunos resolverem novamente aquele teste que havia sido aplicado ao início do curso, diferentemente da primeira vez, onde os alunos tiveram muitas dificuldades, atingindo um índice baixo de acertos, desta vez, os alunos mostraram um melhor empenho, onde depois dos conhecimentos obtidos e exercícios que exigiam o uso do raciocínio lógico durante o curso, as crianças se sentiram aptas e confortáveis a resolver o teste que para eles agora havia se tornado algo de fácil compreensão, uma vez que haviam aprendido a refletir e de fato pensar em todas as possibilidades para se resolver um problema matemático. Este teste se mostrou de extrema importância para concretizar os resultados obtidos pelos alunos e para avaliar de fato se houve um saldo positivo após o curso.

\section{Resultados e discussão}

Após o término do curso, foi novamente aplicado o teste com questões de raciocínio lógico matemático para avaliar se houve melhora no desenvolvimento dos alunos em relação ao teste inicial. Os resultados obtidos após o término do curso se mostraram satisfatórios, a turma que inicialmente obteve um resultado abaixo do esperado, mostrou ao final, um desenvolvimento explícito do raciocínio lógico matemático, no qual foi confirmado através do resultado do teste final, onde os alunos obtiveram uma evolução de 17,6\% em comparação aos conhecimentos obtidos ao iniciarem o curso.

Gráfico 1 - Gráfico dos resultados do teste inicial e final

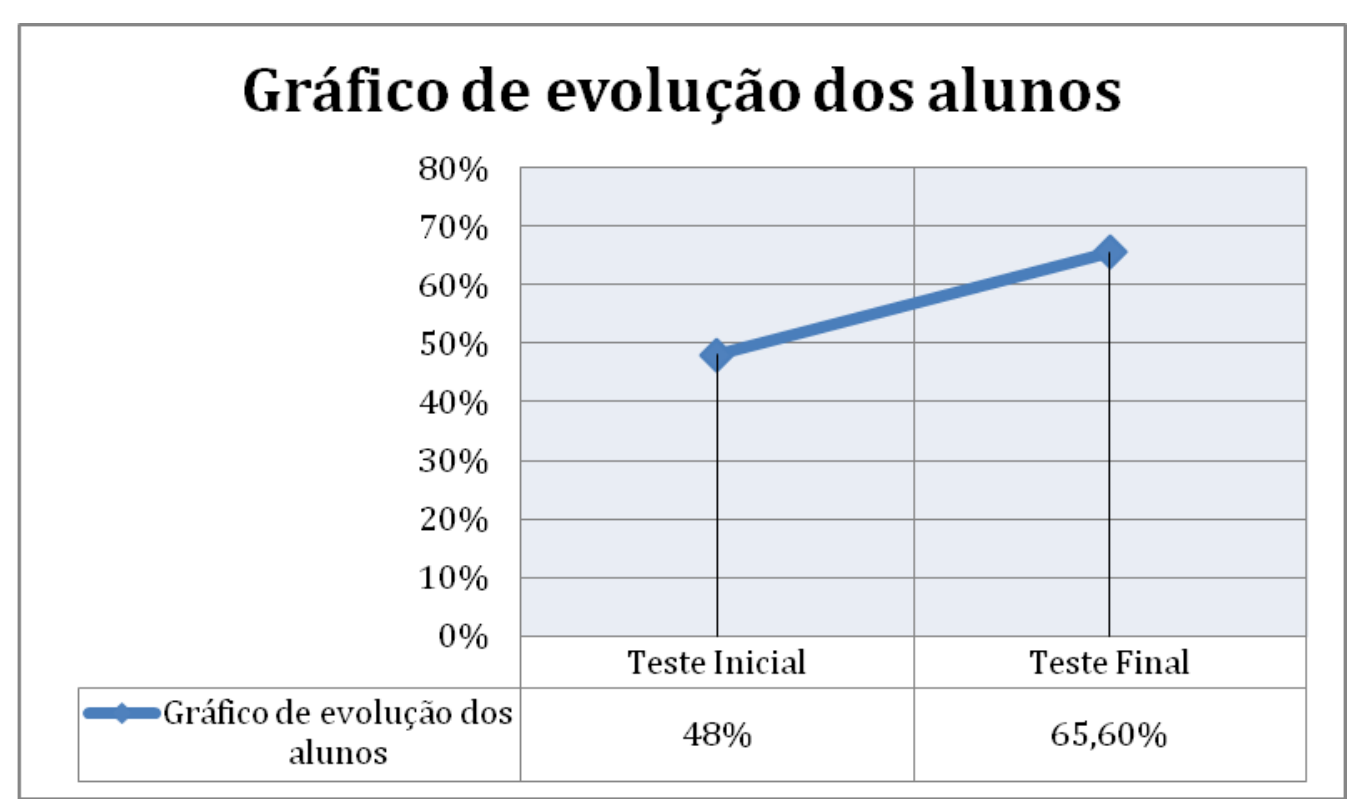

Fonte: Gráfico gerado a partir dos resultados colhidos através do teste aplicado.

Ao longo de todo o curso, os alunos precisaram constantemente pensar para resolver os problemas propostos, onde este simples ato, os fez entender que todo problema dispõe de uma 
BARROS, L, C, A; FREITAS, M, A;

Investigando O Desenvolvimento Do Raciocínio Lógico Matemático Em Crianças Entre 11 E 12 Anos Através Dos Cursos Da Academia Hacktown

maneira prática ou lógica de resolução, principalmente ao se tratar da matemática, que tem em sua composição, a necessidade de concentração e sistematização do raciocínio para chegar aos resultados corretos.

Assim, esses exercícios, tornaram notório o desenvolvimento dos alunos, onde ao decorrer do curso, apresentaram gradualmente formas mais rápidas e práticas para resolver determinados problemas, onde por muitas vezes dispensavam ajuda, por se sentirem capazes de chegar à resolução de qualquer problema.

Os alunos através do curso também aprimoraram outras características, como trabalho em equipe, por serem submetidos diversas vezes a realizarem missões ${ }^{3}$ com auxílio dos colegas, a paciência foi também ao lado da concentração atributos repetidamente exigidos em todas as atividade, assim foi possível ajudar a melhorar o comportamento dos alunos em sala de aula, por serem crianças visam realizar tudo de imediato, eles entenderam que a paciência é fundamental para a resolução de qualquer problema e ao decorrer do curso foram apresentando melhoras nesse aspecto.

Os números comprovaram a necessidade desses alunos experimentarem novas experiências educacionais ou metodologias de ensino como hacktown, onde a evolução mostrada pelos alunos ao longo do curso, tendem a continuar em crescente à medida que os alunos forem dando continuidade na Academia. Sendo que essa evolução ocorreu a alunos novatos na Academia, espera - se uma maior evolução aos alunos que percorrerem o trajeto desde a turma kids 0 , nossa turma inicial até a turma teens, a última turma da academia.

Os resultados colhidos mostram também que a programação estimula o desenvolvimento de disciplinas de exatas, assim, a pesquisa pode ser utilizada como forma de incentivo aos alunos dos cursos técnicos em informática que sentem dificuldades nessas disciplinas, sendo que através dos seus esforços na programação podem melhorar também seus desempenhos em outras matérias como física e também a matemática.

\section{Conclusões}

O curso, em modo geral foi aceito pela sociedade envolvida, onde os pais compreenderam a necessidade de inserir responsavelmente seus filhos na área da tecnologia. Áreas como desenvolvimento de jogos e robótica, junto a todo um corpo que compõe a informática estão em crescente em todo o mundo, sendo assim, obter conhecimentos, trará diversas vantagens no futuro dessas crianças, como mais oportunidades de emprego.

Ao decorrer do curso tornou - se comum os pais relatarem a ansiedade dos seus filhos para ir as aulas e o desejo dos nossos alunos de permanecerem na academia e fazer mais cursos. Onde de fato as metodologias da academia foram aprovadas pelos alunos, que viram na academia uma forma diferente e mais divertida de aprender, diferente dos métodos tradicionais no qual estão acostumados.

\footnotetext{
${ }^{3}$ Denominação da academia para as atividades.
} 
BARROS, L, C, A; FREITAS, M, A;

Investigando O Desenvolvimento Do Raciocínio Lógico Matemático Em Crianças Entre 11 E 12 Anos Através Dos Cursos Da Academia Hacktown

Aprender através de brincadeiras, era algo bastante improvável, sendo que acreditava - se que se o aluno está brincando, não irá se concentrar no que the está sendo ensinado, assim não aprenderá. A academia mostrou que essa junção pode sim funcionar de forma eficiente, entretanto, é necessário filtrar as atividades, e proporcionar aos alunos somente aquelas que façam atribuição ao desenvolvimento dessas crianças.

A academia trouxe a esses alunos do sertão de Pernambuco, além de um novo método lúdico de ensino, tecnologias que antes tinham um acesso improvável por esses alunos, como a utilização do óculos de realidade virtual para proporcionar uma nova experiência aos alunos, a impressora 3D, com intuito de apresentar aos alunos um grande avanço tecnológico que nos permite fazer impressões de objetos, os kits de montagem LEGO EV3, que traz aos alunos uma forma mais simples e divertida de ingressarem na área da robótica e a plataforma Arduino, que oferece aos alunos uma vasta lista de possibilidades, desde a robótica a automação residencial.

Entretanto, não só os alunos da academia foram beneficiados com essas tecnologias, nós bolsistas do projeto e instrutores das aulas, fomos muito beneficiados em vários sentidos, desde o acesso a tecnologias que também não tínhamos acesso ao ingresso na licenciatura, uma experiência que nos trouxe uma nova perspectiva no âmbito profissional, uma vez que por pertencermos a essa área somente como alunos, não tínhamos o conhecimento de como é ser um professor e todas as responsabilidades que estão ligadas a ele. Também foi possível desenvolver algumas características, talvez a principal delas seja a oratória, onde essa oportunidade de ministrar aulas e falar em público para uma turma de alunos sejam eles crianças ou adolescentes nos trouxe uma facilidade para realizar pronunciamentos em público. Sendo assim essa participação no projeto nos proporcionou uma valorosa experiência para traçarmos um futuro acadêmico ou profissional, além de uma rica experiência de vida.

\section{Referências}

AUGUSTO, Lucas; BRANDÃO, Ricardo. Que tal a Hacktown? Revista IF - Sertão PE, Pernambuco, v. 09, 2018.

DA SILVA, J.A.L; OLIVEIRA F.C.S ; MARTINS D.J.S. Storytelling e gamificação como estratégia de motivação no ensino de programação com Python e Minecraft. SBC - Proceedings of SBGames 2017.

FAJARDO, Vanessa; FOREQUE, Flavia. 7 de cada 10 alunos do ensino médio têm nível insuficiente em português e matemática, diz MEC. G1, 2018.

MANSO, A; OLIVEIRA, L; MARQUES, G. C. Portugol IDE - Uma ferramenta para o ensino da programação. Ibero-American Symposium on Project Approaches in Engineering Education (PAEE'2009).

MARTINS, F.C; SOUZA, F.A; HAUS, G.S.P; RODRIGUES, S.S; VIEIRA, A.A. Importância De Trabalhar O Raciocínio Lógico Nas Aulas De Matemática. UFCG. II Conedu. 2015.

METODOLOGIAS. Academia Hacktown Escola Pública de Programação em Jogos e Robótica. 
BARROS, L, C, A; FREITAS, M, A;

Investigando O Desenvolvimento Do Raciocínio Lógico Matemático Em Crianças Entre 11 E 12 Anos Através Dos Cursos Da Academia Hacktown

MOREIRA, M.A. (1999). Teorias de aprendizagem. São Paulo: Editora Pedagógica e Universitária Ltda.

MUNIZ, Camilla. Desenvolver o raciocínio lógico garante melhores desempenhos e fortalece saúde mental. Jornal Extra, 2015.

OLIVEIRA, J.R. O prazer de aprender brincando. Universidade Cândido Mendes, Niterói, RJ, Brasil.

SALDAÑA, Paulo. Desempenho do ensino médio em matemática é o pior desde 2005. Folha de São Paulo, São Paulo, 8 set. 2016. 